\title{
Condylar Dislocation for Intracranial Fossa: a Review of the Last 10 Years
}

\section{Luxação condilar para fossa intracraniana: uma revisão dos últimos 10 Anos}

\author{
Cristóvão Marcondes de Castro Rodrigues ${ }^{1(}$ Jessika Mata do Nascimento $^{2}{ }^{(1)}$ \\ ${ }^{1}$ Department of Medicine, University of Taubaté, Taubaté, SP, Brazil \\ ${ }^{2}$ Department of Dentistry, Centro Universitário do Triângulo Mineiro, \\ Uberlândia, MG, Brazil \\ Address for correspondence Cristóvão Marcondes de Castro \\ Rodrigues, Department of Medicine, University of Taubaté, Av. \\ Tiradentes, 500 - Jardim das Nações, Taubaté - SP, 12030-180, Brazil \\ (e-mail: cristovao-marcondes@hotmail.com).
}

Arq Bras Neurocir 2021;40(4):e361-e363.

\begin{abstract}
Resumo
Palavras-chave

- fossa infratemporal

- côndilo mandibular

- luxações articulares

O deslocamento do côndilo mandibular para dentro da fossa craniana é um evento pouco comum; quando ocorre, existe a necessidade de intervenção cirúrgica imediata e multidisciplinar. Devido ao seu advento raro, ainda não existe uma dinâmica consolidada de atendimento, visto que tal condição ainda não se mostra descrita de forma sedimentada nos bancos de dados literárias. No presente artigo fizemos uma revisão de literatura de luxação condilar para fossa intracraniana descritas nos últimos 10 anos nas bases de busca PubMed e Lilacs.
\end{abstract}

The displacement of the mandibular condyle into the cranial fossa is an uncommon event; when it occurs, there is a need for immediate and multidisciplinary surgical intervention. Due to its rare advent, there is still no consolidated service dynamics, as this condition has not yet been described in a sedimented way in the literature databases. In the present article, we performed a literature review of condylar dislocation for the intracranial fossa described in the past 10 years in the PubMed and Lilacs search databases.

\section{Introduction}

Traumatic dislocation of the mandibular condyle to the cranial fossa is a rare event that occurs after maxillofacial trauma. The main reason for this rare occurrence is that highimpact injuries to the chin usually cause a fracture of the condylar neck, which prevents the violation of the fine glenoid fossa. ${ }^{1}$

The prevalence of such an occurrence may be underreported, since such an event occurs in cases of accidents with high energy dissipation, which consequently are associated with severe neurological damage and high mortality rates of patients. $^{2}$

The clinical features for the diagnosis include ear pain, bleeding from the ear, posterior open and posterior crossbite and limited mouth opening or inability to open the mouth. $^{3}$

For the treatment of this condition, an inter- and multidisciplinary intervention between the neurosurgeon, maxillofacial surgeon, physical therapist, and nutritionist is recebido

28 de Maio de 2021

aceito

13 de Agosto de 2021
DOI https://doi.org/

10.1055/s-0041-1739273. ISSN 0103-5355.

\footnotetext{
(c) 2021. Sociedade Brasileira de Neurocirurgia. All rights reserved. This is an open access article published by Thieme under the terms of the Creative Commons Attribution-NonDerivative-NonCommercial-License, permitting copying and reproduction so long as the original work is given appropriate credit. Contents may not be used for commercial purposes, or adapted, remixed, transformed or built upon. (https://creativecommons.org/ licenses/by-nc-nd/4.0/)

Thieme Revinter Publicações Ltda., Rua do Matoso 170, Rio de Janeiro, RJ, CEP 20270-135, Brazil
} 
required, which makes the management of the case challenging. $4^{4}$

The aim of the present study was to conduct a comprehensive literature review of the past 10 years, referring to traumatic dislocation of the mandibular condyle to the cranial fossa within 2 search platforms to elucidate more this condition within the medical field.

\section{Materials and Methods}

The present review was performed by searching on the following electronic databases: PubMed and Lilacs, with the following descriptors: condyle, intracranial dislocation, trauma, temporomandibular joint and cranial fossa fracture. Data collection was performed at different times. First, all references have been exported to the software Mendeley Desktop 1.13.3 (Mendeley Ltd. London, England) to track possible duplicate records. Studies classified as systematic reviews, original articles, literature reviews, case series, and case reports were included. There was no language restriction and, regarding the publication period, only articles published in the last 10 years (between 2011 and 2021) were selected. The articles whose title and the abstract did not present sufficient information had the full text analyzed, to decide on its eligibility. Those that presented a title within the theme, but the abstracts were not available, were also obtained and analyzed in full. Articles of interest, present in the references of included studies, and which met the eligibility criteria, were also included in the present study.

\section{Results}

The presented flowchart ( - Table 1) demonstrates our selection scheme. After performing applying the inclusion and exclusion criteria adopted for the present review, we arrived at the total of 12 articles that allowed to carry out the present review of the literature on the subject. Of the total number of articles included in the present review, there were two original articles, two case reports, and nine literature reviews associated with a clinical case report. The two original articles bring a broad study on the subject, and even propose an algorithm for the care of patients suffering from condylar dislocation for the intracranial fossa. Two case reports address the open treatment of the lesion. And the other eight articles bring in a concise and objective way about what the literature has on the subject correlating with the presented clinical case, making associative bridges of similarities and differences.

Based on the approach to this issue in the literature, the surgical approach is said to be the choice for all cases, given the associated neurological condition. There is a predilection of occurrence in young males. As it is a high-energy occurrence, it is known that these cases are not always reported because the patient affected by such a condition often presents an unfavorable outcome, considering other associated injuries.

\section{Discussion}

Given the limited number of reported cases, intervention for mandibular dislocation in the middle cranial fossa continues to follow an individualized approach. ${ }^{5}$

The consequences of an impact on the temporomandibular region with condyle intrusion into the cranial fossa may vary due to factors such as the shape or size of the condylar head, pneumatization of the temporal bone, or congenital anomalies of the condyle or glenoid fossa. ${ }^{6}$

On physical examination and imaging, the presence of these fractures is often subtle, therefore, they go unnoticed $^{2,4}$. About $60 \%$ of patients had at least 1 sign associated with a possible injury such as this, including loss of consciousness, impairment of hearing, cranial nerves and association with other cranial fractures. Early diagnosis is essential to avoid unnecessary intracranial management, but also to ensure that the neurosurgery team is available for a possible craniotomy if there is leakage or bleeding of brain fluid, hematoma, or dural rupture. .,7-9 $^{\text {(n) }}$

The literature mentions that a closed reduction under anesthesia should be considered before an open reduction, especially among young patients. Closed reductions are thought to see more success within between 2 and 4 weeks after the injury, and can minimize growth disorders. ${ }^{6,7}$

The preferred strategy is determined by the age of the patient, age of the injury, degree of penetration and proximity to vital structures. The subsequent reduction can be

Table 1 Search strategy

\begin{tabular}{|c|c|c|}
\hline Database & Search Strategy (February, 2019) & Results \\
\hline \multirow[t]{3}{*}{$\begin{array}{l}\text { PubMed } \\
\text { http://www.ncbi.nlm.nih.gov/pubmed }\end{array}$} & $\begin{array}{l}\text { trauma [all fields] AND condyle [all fields] AND intracranial dislocation } \\
\text { [all fields] }\end{array}$ & 9 \\
\hline & $\begin{array}{l}\text { cranial fossa fracture [all fields] AND condyle [all fields] AND intracranial } \\
\text { dislocation [all fields] }\end{array}$ & 8 \\
\hline & $\begin{array}{l}\text { temporomandibular joint [all fields] AND condyle [all fields] AND } \\
\text { intracranial dislocation [all fields] }\end{array}$ & 3 \\
\hline \multirow{4}{*}{$\begin{array}{l}\text { LILACS } \\
\text { http://lilacs.bvsalud.org/ }\end{array}$} & trauma AND condyle AND intracranial dislocation AND (db:(“LILACS”)) & 3 \\
\hline & $\begin{array}{l}\text { cranial fossa fracture AND condyle AND intracranial dislocation AND (db: } \\
\text { (“LILACS”)) }\end{array}$ & 8 \\
\hline & temporomandibular joint AND bone AND cyst AND (db:(“LILACS”)) & 5 \\
\hline & intrusion AND condyle AND intracranial dislocation AND (db:(“LILACS”)) & 1 \\
\hline
\end{tabular}


achieved by the options of open manipulation, condylectomy, and condylotomy, usually depending on the extent of the lesion. ${ }^{4,8}$

The crucial importance of accurate and prompt diagnosis in planning the treatment of these cases requires that computed tomography (CT) scans are ideally performed in these cases to assess the type of displacement. ${ }^{9,10}$

In cases of condyle displacement into the cranial fossa, all require multidisciplinary intervention because they require expertise from maxillofacial and neurological surgeons (especially those with experience in skull base surgery). Long-term monitoring is important, and regardless of the treatment option chosen, the surgeon must be alert to the development of neurological symptoms after open treatment. ${ }^{11,12}$

\section{Conclusion}

In conditions where intracranial condylar dislocation is present, it is of fundamental importance that advanced imaging studies are mandatory for exact diagnosis and successful treatment, and individualized management is recommended, considering the clinical condition of the patient and the riskbenefit component of a surgical intervention, taking into account the neurological condition and functional deficits of the patient, and even the risk of transoperative injuries .

\section{Conflict of Interests}

The authors have no conflict of interests to declare.

\section{References}

1 Arya V, Chigurupati R. Treatment Algorithm for Intracranial Intrusion Injuries of the Mandibular Condyle. J Oral Maxillofac Surg 2016;74(03):569-581. Doi: 10.1016/j.joms.2015.09.033

2 Vaezi T, Rajaei SA, Hosseini Abrishami M, Erfanian Taghvaei M. Dislocation of the mandibular condyle into the middle cranial fossa: a case report. Oral Maxillofac Surg 2014;18(01):69-73. Doi: 10.1007/s10006-013-0395-4
3 Romano N, Fischetti A, Federici M, Castaldi A. Post-Traumatic Intracranial Dislocation of Unfractured Mandibular Condyle. World Neurosurg. 2019 Nov;131:194-195. doi: 10.1016/j. wneu.2019.08.047. Epub 2019 Aug 19. PMID: 31437518.

4 Monteiro JLGC, de Arruda JAA, de Melo ARS, Barbosa RJV, Carneiro SCAS, Vasconcelos BCDE. Updated Review of Traumatic Dislocation of the Mandibular Condyle Into the Middle Cranial Fossa. J Oral Maxillofac Surg 2019;77(01):132.e1-132.e16. Doi: 10.1016/ j.joms.2018.09.011

5 Zhang M, Alexander AL, Most SP, Li G, Harris OA. Intracranial Dislocation of the Mandibular Condyle: A Case Report and Literature Review. World Neurosurg 2016;86:514.e1-514.e11. Doi: 10.1016/j.wneu.2015.09.007

6 Díez-Suárez L, Paredes-Farrera GF. Dislocation of the mandibular condyle into the middle cranial fossa. A case of temporomandibular joint arthroplasty with resorbable fixation system and temporalis myofascial flap: systematic review and meta-analysis. Br J Oral Maxillofac Surg 2021;59(04):389-397. Doi: 10.1016/j. bjoms.2020.08.039

7 Oberman B, Setabutr D, Goldenberg D. Traumatic dislocation of intact mandibular condyle into middle cranial fossa. Am J Otolaryngol 2014;35(02):251-253. Doi: 10.1016/j.amjoto.2013.11.004

8 Sharma D, Khasgiwala A, Maheshwari B, Singh C, Shakya N. Superolateral dislocation of an intact mandibular condyle into the temporal fossa: case report and literature review. Dent Traumatol 2017;33(01):64-70. Doi: 10.1111/edt.12282

9 Rahman T, Hashmi GS, Ansari MK. Traumatic superolateral dislocation of the mandibular condyle: case report and review. Br J Oral Maxillofac Surg 2016;54(04):457-459. Doi: 10.1016/j. bjoms.2015.08.002

10 Rikhotso ER, Bobat MA. Total Alloplastic Joint Reconstruction in a Patient With Temporomandibular Joint Ankylosis Following Condylar Dislocation Into the Middle Cranial Fossa. J Oral Maxillofac Surg 2016;74(12):2378.e1-2378.e5. Doi: 10.1016/j.joms.2016.07.020

11 Rosa VL, Guimarães AS, Marie SK. Intrusion of the mandibular condyle into the middle cranial fossa: case report and review of the literature. Oral Surg Oral Med Oral Pathol Oral Radiol Endod 2006;102(01):e4-e7. Doi: 10.1016/j.tripleo.2006.02.004

12 Ohura N, Ichioka S, Sudo T, Nakagawa M, Kumaido K, Nakatsuka T. Dislocation of the bilateral mandibular condyle into the middle cranial fossa: review of the literature and clinical experience. J Oral Maxillofac Surg 2006;64(07):1165-1172. Doi: 10.1016/j. joms.2006.03.043 